\begin{tabular}{|c|c|c|c|}
\hline Case Reports in & \multicolumn{2}{|c|}{ Case Rep Gastroenterol 2015;9:20-24 } & \multirow[b]{2}{*}{$\begin{array}{l}\text { Karger } \\
\text { Opengaccess }\end{array}$} \\
\hline Gastroenterology & $\begin{array}{l}\text { DOI: 10.1159/000373884 } \\
\text { Publisnea onine. January 17, } 2015\end{array}$ & $\begin{array}{l}\text { ( ) } 2015 \text { S. Karger AG, Basel } \\
1662-0631 / 15 / 0091-0020 \$ 39.50 / 0 \\
\text { www.karger.com/crg }\end{array}$ & \\
\hline & \multicolumn{2}{|c|}{$\begin{array}{l}\text { This is an Open Access article licensed under the terms of the Creative Commons } \\
\text { Attribution-NonCommercial } 3.0 \text { Unported license (CC BY-NC) (www.karger.com/OA } \\
\text { license), applicable to the online version of the article only. Distribution permitted for non } \\
\text { commercial purposes only. }\end{array}$} & \\
\hline
\end{tabular}

\title{
Inappropriate Arginine Vasopressin Levels and Hyponatremia Associated with Cyclic Vomiting Syndrome
}

\author{
Anders Breinbjerg Aksel Lange Soeren Rittig Konstantinos Kamperis \\ Department of Pediatrics, Aarhus University Hospital, Aarhus, Denmark
}

Key Words

Vomiting $\cdot$ Hyponatremia $\cdot$ Vasopressin

\begin{abstract}
We herein describe two children who presented with attacks of severe cyclic vomiting. The primary case was a 2.5 -year-old girl with a history of several admissions with vomiting and altered mental status. She was diagnosed with cyclic vomiting syndrome (CVS). During her attacks she developed significant hyponatremia on several occasions, which prompted us to measure plasma arginine vasopressin (AVP) levels during attacks. We found inappropriately high AVP levels with concomitant hyponatremia. We also measured plasma AVP and plasma sodium in another child with CVS who did not develop manifest hyponatremia but showed inappropriately elevated plasma AVP levels. Since the standard treatment of CVS consists of fluids, high plasma AVP levels may lead to dilutional hyponatremia. We would therefore like to emphasize the importance of close assessment of electrolyte levels in patients with CVS to avoid water intoxication.

(c) 2015 S. Karger AG, Basel
\end{abstract}

\section{Introduction}

Cyclic vomiting syndrome (CVS) was first encountered in the literature in 1861 and the main clinical features were described 21 years later. CVS is an uncommon condition in childhood with an elusive pathophysiological background and a good long-term prognosis. The diagnosis is often challenging, frequently resulting in repeated visits to emergency departments. The diagnostic criteria are three or more recurrent discrete episodes of vomiting, with symptom-free intervals between episodes, and absence of clinical, laboratory and radiographic evidence suggestive of another disease or condition. Episodes are stereotypical in terms of timing of onset, symptoms and duration [1]. Children experience on average 
Breinbjerg et al.: Inappropriate Arginine Vasopressin Levels and Hyponatremia Associated with Cyclic Vomiting Syndrome

12 cycles of vomiting per year [2]. Trigger factors are not uncommon and can comprise stress, infections and lack of sleep. The typical age at onset is early childhood and the syndrome can give place to typical migraine in adolescence and to a lesser degree persist into adulthood.

The pathogenesis of the disease is still unknown, although it is hypothesized that there is a connection between migraine and CVS [3], with high response rates to anti-migraine therapy further supporting this notion. CVS has also been linked to metabolic and mitochondrial disorders, and mitochondrial DNA deletions in children have been described to contribute to the pathogenesis [4]. A family with four members suffering from CVS has also been identified [5], indicating a genetic component of the disorder. Due to the mitochondrial hypothesis, multiple mitochondrial-targeted therapies have been developed, and it is suggested that co-enzyme Q10 and L-carnitine may have an effect [6].

The hormones of the hypothalamic-pituitary-adrenal axis have been related to CVS. Sato et al. [7] described two children with markedly increased pituitary hormones in plasma, including arginine vasopressin (AVP) and adrenocorticotropic hormone, during attacks of cyclic vomiting. Decreased intravascular volume and nausea [8] are potent stimuli for AVP secretion, but Kim et al. [9] also showed that AVP per se may induce nausea when administered intravenously $(0.1 \mathrm{U} / \mathrm{min})$.

The initial treatment for children with an episode of CVS is intravenous fluid therapy, preferably with dextrose solutions [10], anti-emetic therapy, and if necessary analgesics. If the attacks are very frequent and severe, prophylactic treatment with migraine agents such as amitriptyline or cyproheptadine can be considered [11]. Recently valproate, a drug with a known effect on epilepsy, has also been shown to be effective as a prophylaxis for CVS [11]. The mechanisms by which valproate exerts its effects are not yet fully understood, but it seems to increase levels of gamma-aminobutyric acid in the brain and to inhibit sodium channels. We herein describe two cases of CVS: one with inappropriately high plasma AVP levels and concurrent dilutional hyponatremia, and one with inappropriately high plasma AVP levels and no signs of dilutional hyponatremia.

\section{Case Presentation}

The primary case (case 1) concerns a 2.5-year-old girl who was admitted with severe vomiting and dehydration. She was of Philippine and Danish origin and had previously been diagnosed with Turner's syndrome. Since the age of 13 months she experienced recurrent attacks of severe vomiting. The onset of the vomiting episodes was rapid, could consist of up to 50 vomits per day and the duration of an episode was usually 1 week. Based on the clinical characteristics and the absence of other signs of disease, the girl was diagnosed with CVS.

During one of these episodes the girl was admitted with ongoing vomiting and fever, but no clinical signs of dehydration. The initial plasma sodium (PNa) was $133 \mathrm{mmol} / \mathrm{l}$, plasma potassium was $3.4 \mathrm{mmol} / \mathrm{l}$ and hematocrit was $33 \%$. At this point plasma AVP was inappropriately high at $3.17 \mathrm{pg} / \mathrm{ml}$, with a concurrent plasma osmolality at $276 \mathrm{mosm} / \mathrm{kg}$ (fig. 1, the specific measurement is marked by an asterisk). She was treated with intravenous glucose $10 \%$ with $20 \mathrm{mmol} \mathrm{Na} / \mathrm{l}$ and $20 \mathrm{mmol} \mathrm{K} / \mathrm{l}$ at a rate of $40-50 \mathrm{ml} / \mathrm{h}$. The day following admission PNa further declined to $131 \mathrm{mmol} / \mathrm{l}$. During the following days the vomiting slowly improved and PNa returned to normal levels. The girl was discharged after 10 days.

Subsequently, the girl developed hyponatremia on several occasions during her attacks, with PNa values as low as $129 \mathrm{mmol} / \mathrm{l}$. Over a 1-year period she was followed with plasma AVP measurements on 7 occasions (fig. 1). Several of these values were inappropriately high 
Breinbjerg et al.: Inappropriate Arginine Vasopressin Levels and Hyponatremia Associated with Cyclic Vomiting Syndrome

compared to the concurrent PNa levels. Following the tenth attack the girl was treated with valproate $(25 \mathrm{mg} / \mathrm{kg} /$ day) , and the attacks ceased. After more than 2 years of follow-up she is still free of symptoms.

The other case (case 2) concerns a boy, with Somalian parents, born and raised in Denmark. At the age of 7 he was admitted to the hospital with fever, vomiting and diffuse pain in his abdomen. This incidence was considered to be gastroenteritis. At the age of 9 he starts to vomit periodically, with high frequency and rapid onset of vomits. During a period of 1 year he had 9 episodes, with 1-2 months between attacks. Normally, he improved after 2 weeks of intravenous fluid therapy. During an admission, he presented with PNa of $147 \mathrm{mmol} / \mathrm{l}$, plasma AVP of $5 \mathrm{pg} / \mathrm{ml}$, plasma osmolality of $292 \mathrm{mosm} / \mathrm{kg}$ and no clinical signs of dehydration. Three days later, after fluid therapy with glucose solutions, his PNa had decreased to $136 \mathrm{mmol} / \mathrm{l}$, but he did not develop significant hyponatremia during his admission. We measured plasma AVP levels on three other occasions (fig. 1). After the ninth attack he was commenced on valproate (15 mg/kg once daily) as prophylaxis, with prompt effect. He ceased taking the medicine after 8 months and did not experience any symptoms after this.

\section{Discussion}

The initial treatment for CVS is fluid replacement, not only to cover the fluid losses that can be seen during attacks, but it also seems that dextrose solutions may have a direct effect on the condition [12]. However, patients should be closely monitored while on intravenous fluids and electrolytes measured in order to avoid episodes of dilutional hyponatremia, which can result in significant neurological symptoms. Body weight, urine production rate and if possible urine osmolality can be used as indicators of hydration status. Anti-emetics may be given to ease the patient's nausea. Between attacks the treatment must be focused on preventing new attacks. CVS is a disease of unclear pathophysiology and is defined by the characteristics of the vomiting episodes. We herein describe a girl with CVS who experienced episodes of significant hyponatremia during admission and fluid therapy, and a boy who presented with inappropriately high plasma AVP levels during his attacks. Markedly increased levels in plasma AVP have previously been demonstrated in adults with induced nausea [13]. Since we only have a limited number of plasma AVP measurements, it is difficult to directly compare the plasma AVP levels of our patients with the levels seen in that study. Furthermore, it must be noted that in the other study nausea was medically induced, a less physiological clinical setting. Due to the limited number of plasma AVP measurement assessed in our patients during admissions and since AVP has a very short half-life, it is not possible to evaluate whether the values were even higher. The inappropriately high plasma AVP values seen during CVS attacks suggest a role of AVP in the development of hyponatremia. These observations draw attention to this potential serious complication of fluid therapy in children with CVS.

In case 1, hyponatremia ensued during intravenous fluid administration, which represents the first-line treatment of CVS episodes. AVP is secreted from the neurohypophysis in response to osmotic stimuli or hypovolemia. However, a potent stimulus for AVP secretion is nausea, which can lead to excess AVP secretion, and this seems to be the case in children with CVS, as intense nausea is one of the landmark symptoms. This series of events puts the patient at risk for hyponatremia should the intravenous fluid therapy not be adjusted appropriately.

The increased plasma AVP levels seen in the present cases may not just be the result of the intense nausea per se, but may also be part of CVS pathophysiology, as several studies, 
Breinbjerg et al.: Inappropriate Arginine Vasopressin Levels and Hyponatremia Associated with Cyclic Vomiting Syndrome

both in humans and animals, suggest a role for AVP in mediating nausea $[13,14]$. It is however more plausible that the initial episode of vomiting stimulates AVP secretion, thus leading to anti-diuresis and water retention, and the resulting hyponatremia further stimulates nausea and vomiting. Hyponatremia influences the mental status of patients [15], leading to confusion, irritability and fatigue. In figure 1, plasma AVP measurements of both cases during clinical control visits are also shown, and these were within the normal range, thus supporting the thesis.

The first-line treatment of CVS is intravenous fluid replacement with $10 \%$ dextrose solutions [12]. In case of inappropriately high plasma AVP levels, this may lead to a significant fall in PNa. Care should therefore be taken when prescribing fluids in children with CVS, with close monitoring of clinical and laboratory values. A similar line of events is seen in the syndrome of inappropriate anti-diuretic hormone secretion where the patients are effectively treated with fluid restriction.

\section{Conclusion}

The diagnosis of CVS is clinical, with stereotypical episodes of vomiting, altered mental status and lack of other signs of disease. Inappropriately high plasma levels of AVP seem common during the attacks in children with CVS, potentially aggravating the symptoms. Close clinical monitoring (body weight, hydration status, urine output, serum electrolytes) of patient with CVS while on intravenous fluids is essential in order to avoid episodes of dilutional hyponatremia. It is important to adequately evaluate PNa levels to avoid fluid overloading of children with CVS.

\section{Disclosure Statement}

The authors have no conflicts of interest to disclose.

\section{References}

1 Hoyt CS, Stickler GB: A study of 44 children with the syndrome of recurrent (cyclic) vomiting. Pediatrics 1960;25:775-780.

2 Fleisher DR, Matar M: The cyclic vomiting syndrome: a report of 71 cases and literature review. J Pediatr Gastroenterol Nutr 1993;17:361-369.

-3 Li BU, Murray RD, Heitlinger LA, Robbins JL, Hayes JR: Is cyclic vomiting syndrome related to migraine? J Pediatr 1999;134:567-572.

-4 Boles RG, Zaki EA, Lavenbarg T, Hejazi R, Foran P, Freeborn J, Trilokekar S, McCallum R: Are pediatric and adult-onset cyclic vomiting syndrome (CVS) biologically different conditions? Relationship of adult-onset CVS with the migraine and pediatric CVS-associated common mtDNA polymorphisms 16519T and 3010A. Neurogastroenterol Motil 2009;21:936-e72.

5 Haan J, Kors EE, Ferrari MD: Familial cyclic vomiting syndrome. Cephalalgia 2002;22:552-554.

6 Boles RG, Lovett-Barr MR, Preston A, Li BU, Adams K: Treatment of cyclic vomiting syndrome with co-enzyme Q10 and amitriptyline, a retrospective study. BMC Neurol 2010;10:10.

-7 Sato T, Igarashi N, Minami S, Okabe T, Hashimoto H, Hasui M, Kato E: Recurrent attacks of vomiting, hypertension and psychotic depression: a syndrome of periodic catecholamine and prostaglandin discharge. Acta Endocrinol (Copenh) 1988;117:189-197.

-8 Robertson GL: Antidiuretic hormone. Normal and disordered function. Endocrinol Metab Clin North Am 2001;30:671-694, vii.

-9 Kim MS, Chey WD, Owyang C, Hasler WL: Role of plasma vasopressin as a mediator of nausea and gastric slow wave dysrhythmias in motion sickness. Am J Physiol 1997;272(4 Pt 1):G853-G862. 
Breinbjerg et al.: Inappropriate Arginine Vasopressin Levels and Hyponatremia Associated with Cyclic Vomiting Syndrome

10 Boles RG, Adams K, Ito M, Li BU: Maternal inheritance in cyclic vomiting syndrome with neuromuscular disease. Am J Med Genet A 2003;120A:474-482.

11 Hikita T, Kodama H, Nakamoto N, Kaga F, Amakata K, Ogita K, Kaneko S, Fujii Y, Yanagawa Y: Effective prophylactic therapy for cyclic vomiting syndrome in children using valproate. Brain Dev 2009;31:411-413.

12 Li BU, Lefevre F, Chelimsky GG, Boles RG, Nelson SP, Lewis DW, Linder SL, Issenman RM, Rudolph CD; North American Society for Pediatric Gastroenterology, Hepatology, and Nutrition: North American Society for Pediatric Gastroenterology, Hepatology, and Nutrition consensus statement on the diagnosis and management of cyclic vomiting syndrome. J Pediatr Gastroenterol Nutr 2008;47:379-393.

13 Rowe JW, Shelton RL, Helderman JH, Vestal RE, Robertson GL: Influence of the emetic reflex on vasopressin release in man. Kidney Int 1979;16:729-735.

14 Verbalis JG, Richardson DW, Stricker EM: Vasopressin release in response to nausea-producing agents and cholecystokinin in monkeys. Am J Physiol 1987;252(4 Pt 2):R749-R753.

15 Adrogue HJ, Madias NE: Hyponatremia. N Engl J Med 2000;342:1581-1589.
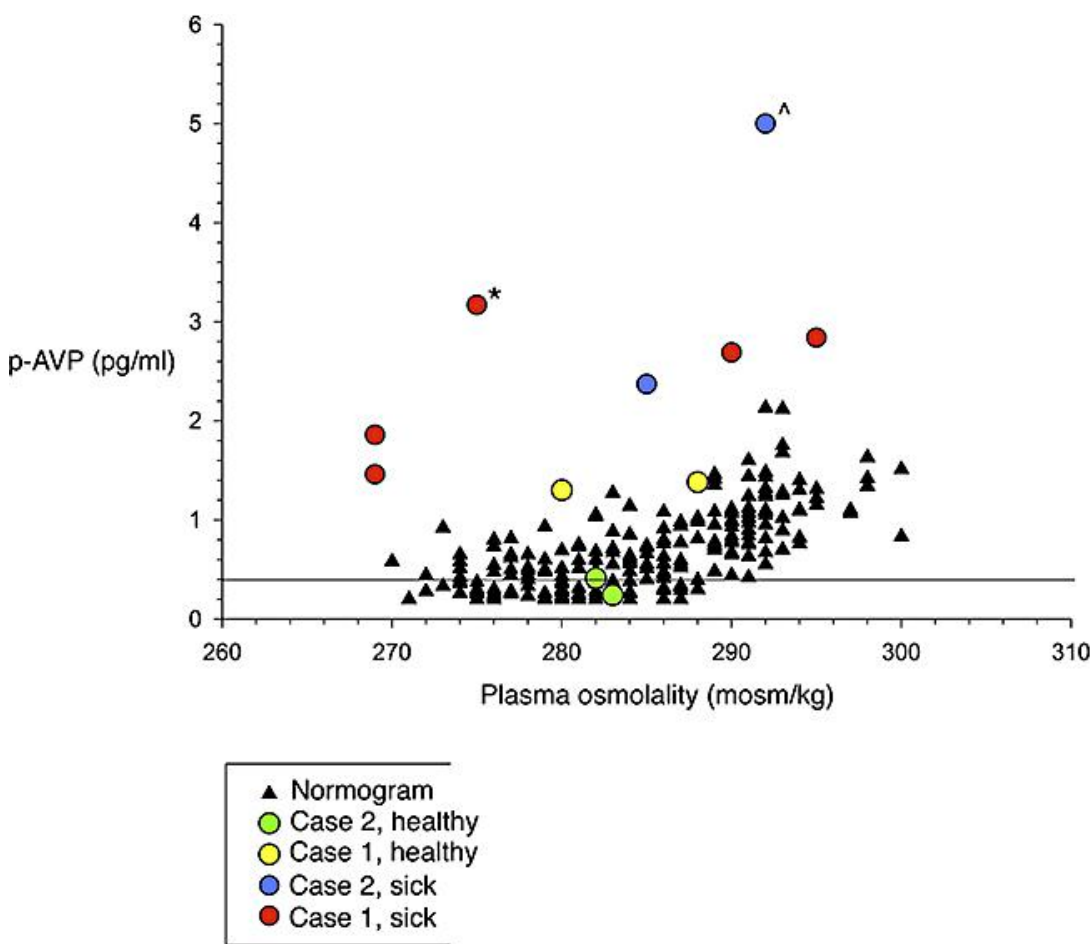

Fig. 1. The cases were followed with plasma AVP (p-AVP) measurements 7 and 4 times, respectively, both during clinical controls where they were clinically well and during admissions with attacks of CVS. The values marked by an asterisk and a caret were taken during the attacks described in the text. 